\title{
Guy de Maupassant, Le Colporteur et autres nouvelles
}

\author{
Ida Merello
}

\section{(2) OpenEdition}

\section{Journals}

\section{Edizione digitale}

URL: https://journals.openedition.org/studifrancesi/26718

DOI: 10.4000/studifrancesi.26718

ISSN: 2421-5856

\section{Editore}

Rosenberg \& Sellier

\section{Edizione cartacea}

Data di pubblicazione: 1 avril 2007

Paginazione: 208

ISSN: 0039-2944

\section{Notizia bibliografica digitale}

Ida Merello, "Guy de Maupassant, Le Colporteur et autres nouvelles», Studi Francesi [Online], 151 (LI | I) | 2007, online dal 30 novembre 2015, consultato il 23 novembre 2021. URL: http://

journals.openedition.org/studifrancesi/26718; DOI: https://doi.org/10.4000/studifrancesi.26718

Questo documento è stato generato automaticamente il 23 novembre 2021.

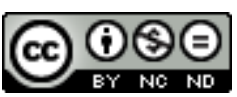

Studi Francesi è distribuita con Licenza Creative Commons Attribuzione - Non commerciale - Non opere derivate 4.0 Internazionale. 


\title{
Guy de Maupassant, Le Colporteur et autres nouvelles
}

\author{
Ida Merello
}

\section{NOTIZIA}

GUY DE MAUPASSANT, Le Colporteur et autres nouvelles, Paris, Gallimard Folio 2006, édition de Marie-Claire Bancquart, préface pp.7-29.

L'edizione riprende il secondo volume di racconti postumi di Maupassant, fatti uscire da Ollendorff nel 1900. L'A.subodora una certa fretta di Ollendorff, per il fatto che riprende cinque racconti già usciti nella prima raccolta, e la ascrive alla volontà di tener viva l'attenzione in attesa dell'edizione delle opere del 1901 e di cavalcare un momento particolarmente favorevole data l'inaugurazione di un monumento allo scrittore a Rouen. Secondo l'A., proprio queste edizioni, che raccolgono testi di genere molto diverso, permettono di renderci conto da un lato dell'ampia gamma di messinscene di situazioni e di sentimenti di Maupassant, dall'altro della sua attività frenetica, dato l'obbligo di scrivere due articoli alla settimana, per la sua collaborazione al "Gaulois" (dal 1880) e al "Gil Blas" (dal 1881). È difficile comprendere come mai lo scrittore, che solitamente pubblicava poi in volume la sua produzione, abbia tralasciato questi racconti. Mentre alcuni sono evidentemente troppo legati ad occasioni contingenti, per altri è più difficile rendersi conto del motivo dell'esclusione, dal momento che sono esemplari della sua sensualità e del gusto per la vita, così strettamente legati tuttavia a un pessimismo di matrice schopenhaueriana. 